\title{
"EL ORO QUE CONTEMPLAN LOS GUSANOS, QUE LO DISFRUTEN LOS HUMANOS". CRUCITAS Y LA DISPUTA POR EL DESARROLLO EN COSTA RICA
}

\author{
Josué Arévalo Villalobos
}

\author{
Recibido: 05/03/2016 Aceptado: 21/05/2016
}

\begin{abstract}
Resumen
Este artículo analiza el conflicto socioambiental de Crucitas teniendo como hipótesis principal que en el fondo se trata de una disputa entre modelos de desarrollo. Se entiende el desarrollo como una matriz discursiva que se expresa culturalmente a través de una triada de sistemas indisolubles: producción, poder y significación. Es un discurso que vehiculiza una serie de prácticas y trae consigo una relación social particular, concreta y capitalista. Crucitas puede comprenderse desde esta óptica, pero debe hacerse en el contexto del tránsito del Consenso de Washington al Consenso de Commodities; en la mutación del discurso del desarrollo sostenible y a la Costa Rica Verde y en el contexto temporal-político en el que se dio la lucha antiminera de Crucitas.
\end{abstract}

Palabras clave: Crucitas; Costa Rica; desarrollo; minería a cielo abierto; minería; conflictos socioambientales.

\begin{abstract}
This article analyzes the Costa Rican environmental and social conflict known as Crucitas proposing as main hypothesis that the conflict is a dispute between two opposing development models. The notion of development is understood as a discourse that expresses itself culturally through a triad of indissoluble systems: production, power and meaning. It is a discourse that drives a set of practices and that includes a capitalist social relation. Crucitas can be understood through this perspective; but in the context of the transition from the Washington Consensus to the Commodities Consensus, when the development speech mutates to the sustainable development and "green" Costa Rica speech. It should also be understood in the timeframe and political context in which the Crucitas struggle against open-pit gold mining took place.
\end{abstract}

Keywords: Crucitas; Costa Rica; development; extractivism; open-pit gold mining; environment; environmental conflicts; territories. 


\section{Introducción}

El proyecto Minero Crucitas que pretendía llevar a cabo la compañía transnacional Infinito Gold generó un amplio movimiento ambiental de oposición en casi todo el territorio costarricense. Este conflicto socioambiental resultó de particular interés porque su duración superó una década y la oposición fue creciendo conforme transcurría el tiempo. Pero, ¿por qué este conflicto generó tanta polémica? La pregunta resulta pertinente, ya que muchas de las acciones de gobiernos y empresas han tenido impactos ambientales graves, y pese a esto no generan tanta resistencia. Así, contestar dicha pregunta requiere pensar las lógicas de acumulación de capital a la luz de las discursividades sobre el desarrollo, y las formas en que estas llevan aparejadas prácticas políticas públicas que desde la cotidianidad sostienen y legitiman al capitalismo.

El caso de Costa Rica es muy particular, en especial por la forma en que se ha ido construyendo la discursividad del desarrollo sostenible y el imaginario de la "Costa Rica verde". Ante esto, la presente investigación busca discutir y problematizar la producción de sentidos, espacios y luchas sociales en torno a un territorio concreto, entendiendo que mediaba la discusión de, al menos, dos modelos de desarrollo contrapuestos. La lucha ideológica sobre la minería a cielo abierto pone en jaque la hegemonía de un sector que promueve la explotación de los recursos naturales por encima del bien común y de la sostenibilidad ambiental. Estas discursividades enfrentadas son, en todo caso, la expresión de la lucha por la tierra y de la lucha anticapitalista, pero con muchos matices.

El conflicto de Crucitas, entonces, tratará de ser interpretado como un problema de modelos de desarrollo opuestos en un contexto histórico particular, en el cual intervienen tanto procesos y disputas por el desarrollo en escala local e internacional, como procesos que no necesariamente eran conscientes para todos los actores. El presente trabajo es apenas un primer acercamiento a esta discusión en el marco de un proceso más amplio de elaboración de un proyecto de Trabajo Final de Graduación de la Maestría Centroamericana de Ciencias Políticas de la Universidad de Costa Rica, por lo que sus resultados y discusiones se tornan parciales.

En la región centroamericana, la minería ha sido propuesta como la alternativa al siempre pospuesto "desarrollo", sin que se considere la alta biodiversidad de los países que componen esta región. Es decir, también existe una equiparación entre extracción, crecimiento económico y desarrollo, en detrimento del ambiente, pues no se considera que la industria minera sea altamente contaminante. Sin embargo, además ha existido a lo largo de las últimas décadas una marcada desregulación a este tipo de actividad, que la ha tornado muy rentable y atractiva para las compañías transnacionales, sumado a los bajos costos de producción y al crecimiento del precio del oro (Nolasco, 2011). 
Solo en el año 2010, el Centro de Investigación sobre Inversión y Comercio (CEI$\mathrm{COM}$ ) contabilizó un total de 420 licencias de explotación minera en Centroamérica (excluyendo a Costa Rica, ya que según la investigación consultada no tenían los datos del país), lo cual representa un $14 \%$ del territorio concesionado. El país con mayor cantidad de concesiones, en ese momento, era Honduras con el 36,9\%, y en términos del total de $\mathrm{km}^{2}$ concesionado en Centroamérica se trata del $66,95 \%$. Por su parte, Guatemala presenta la segunda mayor cantidad de licencias, pero menos territorio concesionado que Nicaragua (15,62 \%), según los datos oficiales del Gobierno. Sin embargo, para Nolasco (2011) es posible que el dato no sea el real, pues algunas organizaciones sociales denuncian que el área concesionada es cuatro veces mayor a la estipulada. En el caso de El Salvador, el área resulta bastante menor, al igual que la cantidad de licencias.

El CEICOM también alertó sobre la relación entre el terreno dedicado a la agricultura y el concesionado a las empresas mineras, el cual siempre resultaba a favor de este tipo de actividad. Se advertía, además, que esta relación podría ser problemática en términos de autoabastecimiento de alimentos, pues daba cuenta de la dependencia comercial de los alimentos y planteaba que las actividades mineras, por su alto grado de contaminación, podrían generar severas consecuencias en la salud y calidad del

ambiente. El informe menciona, además, la pérdida de tierras de comunidades indígenas, la destrucción de bosques, la alteración del paisaje, la contaminación de ríos y fuentes de agua, las enfermedades asociadas a químicos y metales, la erosión, entre otras, como las principales consecuencias de la minería. Estas, por supuesto, varían de un lugar a otro, así como los conflictos.

Al hablar de una región relativamente pequeña, parte de los conflictos que se generan alrededor de los proyectos mineros provoca que algunos de estos se conviertan en verdaderos problemas binacionales, o al menos potencialmente. Por ejemplo, se puede mencionar el caso de la mina Cerro Blanco en Guatemala (ubicada en la zona fronteriza con El Salvador), o del proyecto en Crucitas, muy cerca de la frontera con Nicaragua. En ambos casos los proyectos mineros están cerca de ríos binacionales, y cualquier impacto afectará al ecosistema como tal, aún cuando uno de los dos países tenga legislación más estricta. Se trata de una relación de interdependencia del ecosistema, dividido por fronteras administrativas. Por esta razón, Nolasco (2011) se refiere a estos proyectos como minería transfronteriza, es decir, se da con la expansión de la frontera extractiva y su traslado a las zonas fronterizas de los estados nacionales. El caso planteado en esta investigación no llegó a convertirse en un conflicto binacional, pues no pasó a su fase extractiva; sin embargo, las consecuencias ambientales pudieron llegar al Río San Juan.

\section{Una cronología del conflicto}

Para comprender mejor el caso de Crucitas se hará una cronología del conflicto, la cual puede dividirse en tres etapas: la primera abarca desde la fase de exploración 
hasta la movilización popular que derrota el proyecto (1995-1998); la segunda comprende el periodo 1998-2005 y se califica como una etapa "latencia" en la cual se presenta un limbo jurídico por la moratoria declarada en el 2003, y la tercera inicia con las intenciones de reactivar el proyecto, y finaliza con el fallo del Tribunal Contenciosoadministrativo en el 2011.

Además, se intentará un pequeño ejercicio de contextualización política, al detallar las etapas mencionadas y los principales momentos de la vida del proyecto, haciendo particular énfasis en el gobierno de Óscar Arias Sánchez (2006-2010), cuya administración le da el apoyo final a la aprobación del proyecto, siendo la declaratoria de "interés público" el punto de inflexión definitivo.

El primer intento de explotación minera en la zona de Crucitas inició en 1993, cuando la empresa Placer Dome obtuvo los permisos para la exploración de oro en la Zona Norte. Según Cartagena (2000), en este periodo los principales ejes discursivos de la oposición minera estaban relacionados con un "medio ambiente sano", un "desarrollo local" y una "participación ciudadana en la administración de los recursos naturales". Y es desde estos ejes donde se abordan las identidades sociales en el movimiento de oposición, desarrollo organizativo y niveles de actividad, métodos de la campaña de oposición, la campaña de Placer Dome y los argumentos del debate.

Además, Cartagena plantea que el grupo de oposición a la minería es relativamente pequeño, pero con mucha resonancia, pues según él:

La preocupación por la minería se vincula a la identidad campesina de la población, mientras que los argumentos técnicos-ecologistas son resemantizados por los sujetos a partir de la visión de mundo de su cotidianidad. En el proceso media una reflexión sobre el compromiso social implicado en la ética cristiana de parte de los y las líderes del movimiento (2000: vii).

Esto es muy importante porque ubica en distintos niveles la discursividad y las formas organizativas antimineras, marcando una diferencia entre el discurso urbano ("nacional") y el local, ligado a la vivencia cotidiana. A su vez, el papel de las organizaciones de tipo religioso resulta vital debido a dos factores: fueron los primeros en investigar las denuncias de los vecinos y tenían posibilidades de activar redes, y mantenían una relación estrecha con la naturaleza desde la fe cristiana. Desde este lugar se generó una red de vínculos interpersonales, construyendo sujetos políticos. Siguiendo a Cartagena, el movimiento de oposición no se configura desde lo "objetivo", desde la razón, sino desde lo significativo, lo intuitivo, desde su contexto y desde lo cotidiano. Además, se señala que antes de la lucha contra Crucitas ya había antecedentes de luchas ambientales, lo cual genera referentes simbólicos.

Refiere el investigador que "... lo interesante es que la iniciativa de luchas contra la minería no surgió de ninguno de los proyectos u organizaciones ambientales, 
con la excepción de APAZONO que se incorporó al comité/frente desde la fundación. Este ha sido un movimiento de "vecinos" más que un frente de organizaciones" (2000: 67). Lo importante de esta descripción es que en este primer momento de la lucha contra el proyecto minero fue local, parece que este movimiento de vecinos y sus apoyos externos bastó, sin que la lucha alcanzara el nivel de nacionalización al cual llegó en el segundo momento de avance del proyecto (2005-2012).

Cartagena elabora una línea de tiempo en donde detalla los diferentes momentos de esta primera etapa del conflicto:

- $\quad$ 1993: primeras exploraciones de algunos geólogos en la zona.

- $\quad$ 1994-1995: primeras acciones de información; en 1994 se presenta una queja en la Defensoría de los Habitantes porque los permisos en las áreas de exploración ya contaban con legítimos propietarios y por temor a posibles daños ambientales. En 1995 se organizaba la oposición con la asesoría de AECO.

- $\quad$ 1996: el debate se nacionaliza, académicos, políticos y religiosos debaten sobre conveniencia de la actividad minera. Se crea el Frente Nacional de Oposición a la Minería a Cielo Abierto.

- $\quad$ 1996-1997: en estos dos años el debate se intensifica, así como la organización y acciones locales. En 1997 se publica la fusión de varias empresas, con lo que abarca un total de 33 concesiones con un total de $607 \mathrm{~km}^{2}$.

- $\quad$ 1998: Placer Dome abandona el país. Otras empresas intentan darle continuidad al proyecto.

Como se mencionó, la segunda etapa es de menor intensidad, tras una pausa de algunos años en el conflicto y las intenciones de la compañía minera de iniciar la fase de explotación. Sin embargo, el 17 de diciembre de 2001, mediante la Resolución N. ${ }^{\circ}$ R-578-2001-MINAE, el Ministerio del Ambiente y Energía (MINAE) de Costa Rica otorgó a la empresa Industrias Infinito S.A., filial de la transnacional canadiense Vanesa Ventures, la concesión para explotar la mina de oro a cielo abierto mediante la lixiviación con cianuro. Al mismo tiempo, la presión de los sectores ambientalistas provocó que el entonces presidente Abel Pacheco declarara una moratoria nacional por un plazo indefinido para la actividad de minería metálica de oro a cielo abierto en el territorio nacional (Decreto Ejecutivo N. 30477-MINAE, 5 de junio del 2002).

En julio del 2005, se aprobó un permiso de funcionamiento de la mina Bellavista en Miramar, a pesar de la prohibición decretada a las explotaciones mineras a cielo abierto; a lo cual las autoridades argumentaron que las concesiones fueron otorgadas años antes de la moratoria. En diciembre, la compañía minera inició sus operaciones en medio de una gran oposición de activistas nacionales y organizaciones ambientales internacionales. En respuesta, estas organizaciones y algunos partidos políticos de 
oposición presentaron en la Asamblea Legislativa un proyecto de ley para declarar a Costa Rica país libre de minería de metales pesados a cielo abierto.

Paralelamente, los gobiernos de Estados Unidos, Centroamérica y República Dominicana iniciaron en el 2003 la negociación del Tratado de Libre Comercio; para el 2005 la mayoría ya había firmado, solo en Costa Rica se debatía el tema ampliamente dentro y fuera de las instituciones gubernamentales. En febrero del 2006, Óscar Arias fue reelecto como presidente de la República, y con su llegada nuevamente al poder se prepara una ofensiva neoliberal, cuyo principal objetivo era la aprobación del TLC. El gobierno planteó la discusión en torno al tratado como una oportunidad para generar empleo; otros temas fueron puestos por el movimiento en la primera línea de discusión, como por ejemplo el ambiental. Tras una intensa polarización política, el tratado finalmente fue aprobado mediante un referéndum en el año 2007 con un estrecho margen para el "Sí".

De este modo, el tema ambiental se había instalado en la "opinión pública" como punto de discusión, por lo que Óscar Arias y su gobierno lanzaron el plan "Paz con la naturaleza", para tratar de silenciar las voces disidentes por el claro tinte mercantil con que se estaban gestionando los temas ambientales. Para el Gobierno se trataba de retomar la "agenda verde y -particularmente- el café". Según las autoridades, la primera había acaparado toda la atención, y se dedicó mucho tiempo "a vender el país por la parte forestal y de áreas protegidas".

Un hecho que avivó la discusión en torno a la minería a cielo abierto ocurrió el 22 de octubre del 2007, cuando un derrumbe provocó que quedara semienterrada la planta de procesamiento y parte de la pila de lixiviados de la mina de Miramar. Con este hecho se agregó un nuevo elemento a la discusión en torno a la minería. A pesar del derrumbe y del plan "paz con la naturaleza", el gobierno de Óscar Arias, decidió, el 18 de marzo del 2008, derogar la moratoria minera que establecía el Decreto Ejecutivo N. 30477-MINAE y, en su lugar, se dictó un nuevo decreto que establecía una "salvaguarda ambiental para la minería".

Siete meses después, el 13 de octubre del 2008, mediante el Decreto Ejecutivo N. ${ }^{\circ} 34801-M I N A E T$, el entonces presidente Óscar Arias Sánchez declaró de interés público y conveniencia nacional el Proyecto Minero Crucitas desarrollado por la empresa Industrias Infinito S.A., el decreto autoriza la tala de 191 hectáreas. Una semana después de la publicación del decreto, la Asociación Norte por la Vida (UNOVIDA) presentó un recurso de amparo en contra del presidente de la República, su ministro de Ambiente (MINAET), y, por ende, del decreto ejecutivo. Con este recurso, la Sala Constitucional paralizó las obras y el debate público se volvió más intenso.

El 29 de octubre del 2008, la Universidad de Costa Rica entró en el debate público y el Consejo Universitario se manifestó en contra de la declaratoria de interés público y conveniencia nacional del Proyecto Minero Crucitas. En el pronunciamiento, la 
Universidad advirtió sobre posibles daños ambientales y argumentó que la declaratoria de interés público violenta el derecho a un ambiente sano. Además, en sus considerandos el Consejo Universitario indicó que

... es necesario analizar factores sociales, culturales, politicos, ambientales, y no solo estimaciones económicas, para determinar la conveniencia nacional de abrir los ecosistemas a la explotación minera (...) Es necesario fortalecer la visión ambientalista de la protección de la biodiversidad y de los ecosistemas, para contrarrestar el predominio de la concepción mercantilista que se ocupa principalmente de la valoración monetaria del medio ambiente y su definición como bien económico.

Con este pronunciamiento, la Universidad ingresó en la disputa como un actor más en contra de la minería, y lo hizo al enfatizar en los criterios técnico-científicos, y al cuestionar la visión del desarrollo que pone por encima una "concepción mercantilista", la cual hace una valoración monetaria del desarrollo y, por tanto, subordina el ambiente a la obtención de ganancias económicas.

Casi dos años después de presentado el recurso de inconstitucionalidad, el 15 de abril de 2010, ahora con Laura Chinchilla en la presidencia, la Sala Constitucional declaró sin lugar el recurso y dio vía libre para la construcción de la mina; este fallo reabrió nuevamente la polémica y puso cuestionamiento la imparcialidad del Tribunal Constitucional. Ante el rechazo del recurso, diversas organizaciones ambientalistas y UNOVIDA presentaron un nuevo recurso, esta vez ante el Tribunal Contencioso Administrativo (TCA), que detiene las obras en la Zona Norte hasta que no se resuelvan los cuestionamientos planteados al tribunal. La Procuraduría General de la República (PGR) apeló el recurso presentado por los ambientalistas.

Días después, el 21 de abril del 2010, un grupo de ambientalistas realizó una representación teatralizada de los daños ambientales que podría generar el proyecto minero. Durante la protesta, los manifestantes hicieron un hueco en la Fuente de la Hispanidad con tractores de cartón, picos y palas, simulando la minería a cielo abierto. Al día siguiente otra acción de protesta tuvo lugar frente al edificio de la Corte Suprema de Justicia en el Circuito Judicial de San José. La marcha concentró a estudiantes universitarios, colegiales, organizaciones ambientalistas, sociales, comunales, sindicales, quienes expresaron críticas al "Plan Paz con la naturaleza" impulsado por Óscar Arias. El conflicto se judicializó, y fue finalmente resuelto en estas instancias; los ambientalistas denominaron este acto como un claro "contubernio entre el Estado y la empresa canadiense Industrias Infinito".

A finales de abril del 2010, un funcionario del Servicio Nacional de Aguas Subterráneas, Riego y Avenimiento (SENARA), de apellidos Ramírez Hernández, denunció la carencia de estudios hidrogeológicos que justificaban la viabilidad del proyecto 
minero avalado por la Sala IV. En su denuncia, Ramírez invocó los principios éticos y de conciencia ambiental, alegando defender la institucionalidad, e hizo un llamado para fortalecer a la institución con recursos económicos y humanos. Semanas más tarde, en mayo del 2010, el Concejo Municipal de San Carlos se pronunció en contra de la minería a cielo abierto y, concretamente, contra el proyecto minero en Crucitas. El Concejo estaba controlado por una coalición formada por los partidos Acción Ciudadana, Alianza Sancarleña, Renovación Costarricense y el Movimiento Libertario, opositores del Partido Liberación Nacional (PLN) y el Partido Unidad Social Cristiana (PUSC). En el acuerdo del Concejo Municipal se solicitó a la presidente Chinchilla anular todos los permisos otorgados a Industrias Infinito S.A.

Finalmente, en noviembre del 2010, la Asamblea Legislativa aprobó la Ley 8904, Ley para Declarar a Costa Rica País Libre de Minería de Metales Pesados a Cielo Abierto, la cual entró en vigencia en febrero del 2011. Ese mismo mes, el Tribunal Contencioso Administrativo, en una sentencia histórica, ordenó cancelar la concesión minera del proyecto Crucitas, y le solicitó a la fiscalía revisar si existía mérito para acusar de prevaricato a los funcionarios públicos que autorizaron y promovieron la declaratoria de interés público para el proyecto minero de Crucitas, entre los funcionarios a investigar se encontraba Óscar Arias y Roberto Dobles. Por este asunto Arias nunca fue procesado, aunque Dobles sí fue condenado.

Resulta interesante hacer notar que durante el gobierno de Arias la discusión en torno al TLC generó, como ya se mencionó, una gran polarización social, y hubo muchas denuncias por concentración de poder, pues existían las sospechas de que desde el Poder Ejecutivo se socavaba la independencia de los demás poderes. Por ejemplo, la Sala IV emitió un polémico (y dividido) fallo sobre los posibles roces constitucionales del Tratado, y una mayoría de los magistrados dictaminó que estos no existían. El mismo Tribunal Constitucional también avaló, en un primer momento, el proyecto minero, y fue otro Tribunal (el Contencioso) el que finalmente dictaminó la ilegalidad de lo ejecutado en las instituciones; razón por la cual ordenó abrir un expediente judicial. Es decir, aunque en esta contextualización se ha hecho referencia a las acciones del Gobierno para aprobar a toda costa la explotación minera, en el marco del Estado había contradicciones y equilibrios al poder del Ejecutivo, y que a pesar de las múltiples denuncias (e incluso evidencias) de la creciente cooptación a las instituciones y Poderes de la República, se aprobó un proyecto de ley para prohibir la actividad minera y un Tribunal dictó, de forma independiente una sentencia judicial en la cual señalaba ilegalidades.

De forma esquemática, puede presentarse la cronología del conflicto de la siguiente manera: 
Figura 1

LÍNEA DEL TIEMPO DEL CONFLICTO EN CRUCITAS

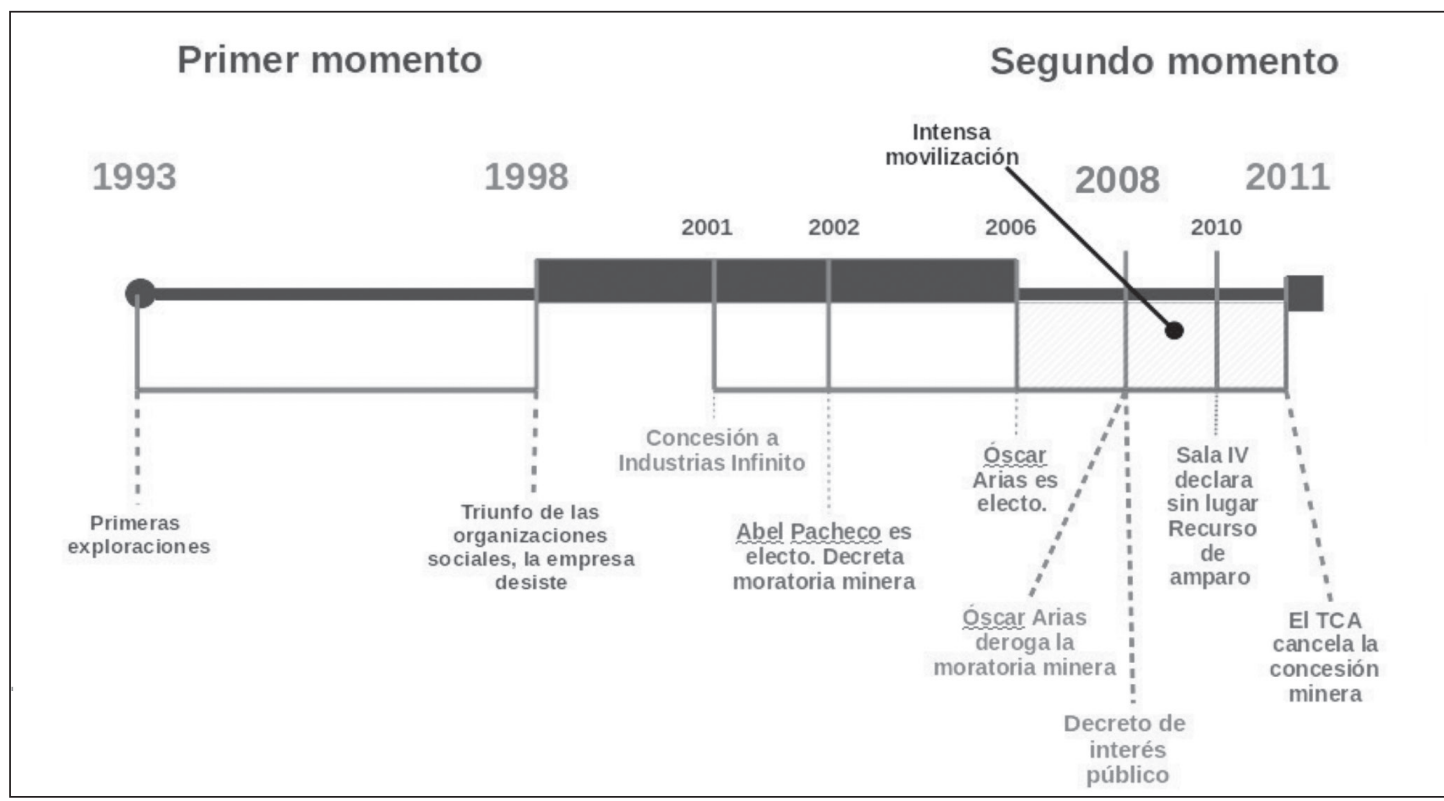

Fuente: Elaboración propia.

En esta figura se traza una línea de tiempo del conflicto minero, poniendo el acento en el "segundo momento del conflicto". El periodo que va desde 1998 hasta el 2006 marca un momento de baja movilización tras el triunfo de las organizaciones sociales. Como ya se detalló, esto no quiere decir que el conflicto finalizara. Con la concesión a Industrias Infinito en el 2001 y la moratoria declarada por Abel Pacheco, el conflicto adquiere otras características. Sin embargo, sin duda el punto de inflexión es la línea roja marcada en el 2008 con la derogatoria de la moratoria y la declaración de interés público; lo cual se reflejó en el intenso periodo de movilización social desde el 2006 hasta el 2011, en lo que particularmente se refiere a Crucitas.

En la actualidad, el proceso ha entrado en una nueva etapa, pues Industrias Infinito anunció que demandará a Costa Rica ante el Tribunal de Arbitraje Internacional (CIADI), con lo cual se abre un nuevo debate con el sector ambiental. El Gobierno debería negarse a asistir al arbitraje, pues, según el Tratado de Libre Comercio con Canadá, para que un conflicto pueda ser objeto de este procedimiento, no debe haberse agotado la instancia judicial local, lo cual ya ocurrió. 


\section{El "Consenso de Commodities": Latinoamérica como abastecedora mundial de materias primas}

Según datos del Observatorio de Conflictos Mineros de América Latina (OCMAL), solo en el 2014 la región había captado el 27 \% de la inversión minera a nivel mundial. Este crecimiento de la inversión tiene un correlato de afectación en el territorio, pues la misma OCMAL señala que al expandirse la frontera extractiva se ven afectados diversos e importantes ecosistemas como los páramos, los sistemas de lagunas altoandinas, las cabeceras de cuencas, la Amazonía o los glaciares. Por su parte, Nolasco (2011) señala que este aumento de la inversión responde al incremento en los precios del oro a nivel internacional (562 \% en el periodo 19952010) producto de la crisis, y al ser considerado como un activo seguro, existe un debate en torno a si es recomendable o no regresar al patrón oro. Esto por supuesto viene a acentuar una tendencia al alza, y a la expansión de esa frontera de extracción que señala el OCMAL.

Desde hace varios años, el capitalismo neoliberal ha facilitado las condiciones para que la actividad minera sea primaria en la región latinoamericana. Durante los noventa, una serie de desregulaciones económicas y fiscales, las privatizaciones y la introducción del modelo de agronegocios fueron puestas en marcha, sentando así las bases de un Estado metarregulador; ante esto, la generación de una legislación favorable para la implantación de capitales extranjeros institucionalizó los "derechos" de las grandes corporaciones. Al tiempo que esto consolidó un modelo en muchos países latinoamericanos de economías reprimarizadas dependientes de los mercados externos, con tendencias patrimonialistas. Según Svampa el “... Estado "metarregulador" es el responsable de crear el espacio para la legitimidad de los reguladores no estatales..." (2009: 31).

Aunque el discurso neoliberal insista en que se trata de menor intervención del Estado, se refiere más bien a un tipo diferente de intervención estatal, de donde emerge una nueva forma de "gobierno indirecto", en el que los actores económicos tienen poder para controlar los recursos esenciales, y no están sometidos a ningún tipo de control por parte de la sociedad o el mismo Estado.

Este modelo se caracteriza por la generalización del extractivismo exportador, el cual se basa en la explotación de recursos naturales no renovables que alimentan el consumo sostenido y la acumulación de capital (Svampa, 2009). De acuerdo con la socióloga argentina Maristella Svampa, Latinoamérica ha pasado del Consenso de Washington al "Consenso de Commodities", lo cual se debe a un nuevo orden que 
... va consolidando un estilo de desarrollo neoextractivista que genera ventajas comparativas, visibles en el crecimiento económico, al tiempo que produce nuevas asimetrías y conflictos sociales, económicos, ambientales y político-culturales. Tal conflictividad marca la apertura de un nuevo ciclo de luchas, centrado en la defensa del territorio y del ambiente, así como en la discusión sobre los modelos de desarrollo y las fronteras mismas de la democracia (2013: 30).

Svampa (2013) utiliza el concepto de commodities para referirse a todos aquellos productos de fabricación y disponibilidad mundial, cuyo precio es fijado internacionalmente, y no requieren tecnología avanzada para su procesamiento o fabricación. Lo anterior incluye desde materias primas a granel hasta productos semielaborados o industriales; en el caso de la región latinoamericana esa demanda es fundamentalmente de productos agrícolas (maíz, soja y trigo), hidrocarburos (gas y petróleo), metales y minerales (cobre, oro, plata, estaño, bauxita, zinc, entre otros).

Aunque la explotación y exportación de este tipo de bienes naturales no es una actividad nueva en Latinoamérica, los cambios en el modelo de acumulación y el agotamiento de los recursos a nivel mundial ha hecho que se expandan los proyectos de extracción, sin que esto implique necesariamente, mayor valor. Este nuevo "consenso", desde el punto de vista de Svampa, "apunta a subrayar el ingreso a un nuevo orden económico y político, sostenido por el boom de los precios internacionales de las materias primas y los bienes de consumo, demandados cada vez más por los países centrales y las potencias emergentes" (2012: 16), lo que ha llevado a un reprimarización en las economías latinoamericanas. Con ello se asigna un lugar particular a la región en la división del trabajo a nivel internacional. Para Horacio Machado Aráoz es

... interesante observar cómo, a escala mundial, «la geografía de la extracción es muy diferente a la geografía del consumo». Por ejemplo, América Latina produce 26,2\% de la bauxita en el mundo, pero solo consume 2,9\%; en cuanto al cobre, produce 45,1\% y consume 6,1 \%; respecto del oro, produce 15,2 \% del total mundial y consume $3 \%$ (citado por Svampa, 2013: 31).

Esta geografía de la extracción, indica que ese punto en la producción mundial de mercancías sostiene un orden capitalista global en donde se asigna un lugar a la región, es decir, se trata de la extracción de recursos naturales para consumo del primer mundo. En otras palabras, se refiere a una lógica irracional, insostenible, que dejará réditos en el corto plazo, pero que si no se detiene agotará las fuentes que sostienen el progreso actual.

Esta lógica de extracción de los recursos

... por un lado, contribuye a acentuar las lineas de continuidad entre un momento y otro [Consenso de Washington y el Consenso de Commodities], porque efectivamente tanto las transformaciones sufridas por el Estado nacional como la politica de privatizaciones de los 
bienes públicos operadas en los noventa sentaron las bases normativas y jurídicas que permitieron la actual expansión del modelo extractivista, garantizando "seguridad jurídica" para los capitales y una alta rentabilidad empresarial, que en líneas generales serían confirmadas -con sus variaciones especificas-durante la etapa de los commodities (Svampa, 2013: 18).

Por tanto, este consenso de commodities en alguna medida traza y sintetiza continuidades y rupturas (sobre todo en los países con gobiernos progresistas) que podrían considerarse "posneoliberales", sin que ello implique la salida del modelo neoliberal. La contradicción está ahí instalada, mientras Latinoamérica ocupa un lugar prominente en la producción de materias primas en la división internacional del capital y algunos países implementan políticas sociales financiadas con la exportación de esas materias, las corporaciones transnacionales siguen acumulando capital; razón por la cual se está llegando al límite de regeneración de la naturaleza y se despoja a poblaciones enteras de sus territorios bajo la idea (ilusión) de progreso. Esto cuando hay un esfuerzo estatal por reducir la vergonzosa e injustificable desigualdad de nuestra región, porque cuando estos esfuerzos ni siquiera son planteados, el despojo se torna simplemente violento.

Con este marco de fondo, una de las preguntas que cabe hacerse es ¿cómo, desde el Estado, se cumple con la obligación (deuda) histórica de generar bienestar para las grandes mayorías si a la región, en esta división internacional de la producción, se le ha asignado un lugar de productor de materias primas? Y para mayor complejidad, se agrega un elemento más: tradicionalmente las izquierdas han puesto el énfasis en la lectura política desde la contradicción capital-trabajo, dejando de lado la tensión entre esa díada con las cuestiones territorial-ambientales y los bienes comunes. $\mathrm{Al}$ respecto Svampa señala:

En este marco político-ideológico tan cegado por la visión productivista y tan refractario a los principios del paradigma ambiental, la actual dinámica de desposesión se convierte en un punto "ciego", no conceptualizable. Como consecuencia de ello, las problemáticas socioambientales son consideradas como una preocupación secundaria o lisa y llanamente sacrificable, en vistas de los graves problemas de pobreza y exclusión de las sociedades latinoamericanas (2013: 37).

Esta es la cuestión de fondo en la discusión por los recursos: en la lucha anticapitalista se requiere de una nueva lógica. No es posible sostener el crecimiento económico, mientras se pretende hacer sostenible al desarrollo. Como afirma el presidente boliviano Evo Morales:

Hemos llegado a un limite y hay que tomar acciones mundiales urgentes para salvar a la sociedad, a la humanidad y a la Madre Tierra ... [es necesaria] una Revolución Democrática y Cultural que destierre la exclusión, la explotación, el hambre, el odio, para reconstruir el camino del equilibrio, de la complementariedad, del consenso con identidad propia, del Vivir Bien (2014). 
Sin embargo, este planteamiento es, para Svampa, el más contradictorio del consenso de los commodities. Y es que no es un tema menor,

... dado que ha sido en estos países [Bolivia y Ecuador] donde, en el marco de fuertes procesos participativos, se han ido pergeñando nuevos conceptos-horizonte como los de descolonización, Estado plurinacional, autonomías, «buen vivir» y derechos de la naturaleza. Sin embargo, y más allá de la exaltación de la visión de los pueblos originarios en relación con la naturaleza (el «buen vivir»), inscrita en el plano constitucional, en el transcurrir del nuevo siglo y con la consolidación de estos regimenes, otras cuestiones fueron tomando centralidad, vinculadas a la profundización de un neodesarrollismo extractivista (Svampa, 2013: 38-39).

\section{La minería y el discurso del desarrollo}

Existe una estrecha relación entre el discurso del desarrollo y la minería, especialmente la megaminería. En el caso particular de esta actividad ocurre algo muy particular: su fundación tiene como origen una regulación desde la inhibición del Estado para disponer del territorio, al despojar a comunidades enteras de sus recursos y medios de supervivencia. Se trata de una supranación y la renuncia explícita a la soberanía, una legislación producida a escala de los intereses de las corporaciones transnacionales (Antonelli, 2009).

Lo anterior resulta importante porque esta construcción jurídica sostiene un discurso que se ha hecho hegemónico, en el cual las empresas transnacionales de la minería tratan de tomar acuerdos con el objetivo de generar consenso -sentidos comunes, como lo entendía Gramsci- en torno a su actividad. Se trata de un dispositivo que funciona como

... una red de relaciones entre instancias y elementos heterogéneos: discursos, instituciones, arquitectura, reglamentos, leyes, medidas administrativas, enunciados cientificos, proposiciones filosóficas, morales, filantrópicas, lo dicho y lo no dicho. El dispositivo establece la naturaleza del nexo que puede existir entre estos elementos y, como tal, agregamos nosotros, atraviesa al Estado, lo incluye. La "colonización" de las representaciones sociales o producción social de sentidos nombre un proceso-efecto marcado por la celeridad, la focalización de centros de irradiación y la capacidad de saturación y sutura de discursos sociales aparentemente no relacionados, producidos por instituciones y actores de diferentes espacios, esferas y marcos de actividades (Antonelli, 2009: 53).

En otras palabras, se refiere a un discurso que se hace hegemónico al articular “... condensadores de sentido en la narrativa promesante del "desarrollo sustentable", con la que gestiona y busca modelar y modular las proyecciones del futuro "gracias a la minería", interviniendo memorias y significaciones del presente" (Antonelli, 2009: 54). 
Así, el objetivo fundamental es construir consensos y promover negociaciones que favorezcan la megaminería, no solo a lo interno de un Estado-nación, sino también en donde este tipo de compañía busque instalarse.

Concretamente, y según la descripción que hace Antonelli (2009), se trata de todo un entramado que enlaza capital transnacional, operadores, mediadores, Estado e instituciones, lo cual es vital para que los proyectos mineros tengan viabilidad formal, y así se institucionalice está lógica extractiva. Se trata de un funcionamiento en el que se reproducen subjetividades que se anudan en torno a una legalidad, que a su vez legitima discursos y prácticas generadas desde el Estado y las empresas transnacionales.

De esta forma, dentro del marco del Estado se producen discursividades, múltiples, diversas e incluso contradictorias, pero no se habla un único discurso, ya que

El Estado forma parte del dispositivo hegemónico en sus múltiples instancias de enunciación, con la particular necesidad de reforzar en simultaneidad la lógica del capital y la lógica del campo político. Teniendo en cuenta que la Nación ha declarado la minería como "plan nacional", esto es, le ha asignado el carácter de "interés público" (...) ha puesto todos sus aparatos -legal, técnico, económico, social, cultural, de producción, innovación y transferencia de conocimientos-al servicio del modelo extractivo de los capitales transnacionales... (Antonelli, 2009: 55).

\section{Crucitas y las miradas del desarrollo}

Los caminos en mal estado, llenos de lodo y rodeados de casas desocupadas, en Crucitas de Cutris, retratan el olvido de un pueblo al que le prometieron oro, pero

terminó estancado en el olvido y la desolación Barrantes, Alberto y Hernández, Carlos La Nación, 8 de enero de 2014

Este epígrafe es parte de un reportaje escrito por los periodistas Alberto Barrantes C. y Carlos Hernández, y brinda una versión sobre el abandono sufrido por el pueblo de Crucitas. Si se presta atención, se puede notar que este epígrafe (y el reportaje entero) tiene implícito una visión particular del desarrollo, o de lo que la empresa consideró debió ser el desarrollo de esa zona.

La descripción inicial, Los caminos en mal estado, llenos de lodo y rodeados de casas desocupadas..., brinda una imagen del estado del pueblo de Crucitas, se trata de una mirada particular, una mirada de un pueblo "sin desarrollo". Es decir, de un otro que mira desde afuera, que se posiciona de un lado particular, y que claramente asume un discurso específico. A Crucitas le prometieron (el Gobierno y una compañía transnacional minera) el oro (desarrollo), y esa promesa incumplida 
(más adelante en el artículo se señala a los culpables) ha dejado al pueblo "estancado en el olvido y las desolación”. Este es el retrato del olvido, pero ¿de quién es la responsabilidad? Lo que subyace acá es una valoración positiva de la minería, se trata de una unidireccionalidad discursiva.

Resulta interesante la descripción que hacen los periodistas, porque asumen un discurso desarrollista, pues para ellos hay culpables del "retraso" (nodesarrollo) de la comunidad: ambientalistas que no permitieron la explotación de minería de oro a cielo abierto. El movimiento ideológico en el reportaje es evidente: si el desarrollo no llega es culpa de los ambientalistas, lo cual supone que la explotación de oro equivale a desarrollo -tal y como lo prometía la compañía transnacional Infinito Gold-, es decir, se comprende la extracción de recursos naturales como algo que debe suceder para que los caminos estén en buen estado y sin lodo, y las casas se encuentren ocupadas. Es la mirada del un observador externo, pero no imparcial, la de quien dicta cuál es el modelo a seguir y califica al otro de pobre, subdesarrollado, y además señala a los culpables de ese subdesarrollo, es la mirada de un sector que busca hegemoneizar esa mirada y traducirla en una praxis concreta. De este modo, el artículo alude a la vieja idea de que crecimiento económico es igual a desarrollo, subordina bienestar humano, equilibrio ambiental, desigualdad y pobreza a un criterio economicista.

La fotografía da cuenta de un camino lodoso, en evidente mal estado, casi intransitable; el pie de foto tiene una sentencia muy clara, un camino abandonado y un poblado vacío, porque la minera salió; ergo, si la minera no se "hubiese ido" el camino no estaría abandonado y el poblado no se encontraría vacío. Puede interpretarse con facilidad que el deterioro es producto de la salida de la empresa, lo cual oculta que la zona ha estado abandonada durante décadas por todos los gobiernos de turno.

Este pequeño ejemplo de un discurso de un actor político concreto (La Nación) muestra la síntesis de una matriz discursiva que se expresa culturalmente a través de una tríada de sistemas indisolubles: producción, poder y significación. Así, la economía, según Escobar (2014), es una producción cultural, "una forma de producir determinados seres humanos y órdenes sociales" (114). Por lo tanto, resulta útil comprender el desarrollismo como ámbito de la discursividad y de la representación, y, como tal, deviene en prácticas concretas de pensamiento y en acciones particulares. Al respecto, este autor sugiere que el desarrollo es un discurso producido históricamente, capaz de crear una relación social determinada. De lo que se trata entonces es de la "colonización de la realidad", y de "... cómo ciertas representaciones se vuelven dominantes y dan forma indeleble a los modos de imaginar la realidad e interactuar con ella" (Escobar, 2014: 51).

Durante décadas, este discurso ha construido un sentido común, pues plantea la forma en la cual debe funcionar el medio; idea que forma parte del sentido común precisamente porque se fortalece sobre otro discurso anterior y asumido en Latinoamérica 
de forma particular: la idea de progreso. América Latina ocupa un lugar particular en esta idea de progreso, se trata de un régimen de representación "... como lugares de encuentro de los lenguajes del pasado y del futuro (tales como los lenguajes de ‘civilización y barbarie de la América latina posindependentista, lenguajes externos e internos y lenguajes de sí y de los otros" (Escobar, 2014: 57). Así, el desarrollo como discurso vino acompañado "de formas específicas de violencia modernizada" y produjo formas de conocimiento y poder, en otras palabras, es un discurso de dominación, un espacio cultural que se vuelve certeza en el imaginario social.

Gudynas, por su parte, señala que desde mediados del siglo XX, el desarrollo fue equiparado con el concepto de crecimiento económico, y por tanto se asumió que el Producto Interno Bruto (PIB) era un indicador adecuado para medir el desarrollo, consolidando una visión economicista y lineal “... mediado por la apropiación de recursos naturales, guiado por diferentes versiones de eficiencia y rentabilidad económica, y orientado a emular el estilo de vida occidental" (2012: 23).

Para Escobar lo que está en juego

... es el proceso mediante el cual, en la historia occidental moderna, las áreas no europeas han sido organizadas y transformadas sistemáticamente de acuerdo con los esquemas europeos. Las representaciones de Asia, África y América Latina como "Tercer Mundo" y "subdesarrolladas" son las herederas de una ilustre genealogía de concepciones occidentales sobre esas partes del mundo (2014: 53).

Estas regiones son asumidas de forma natural también a lo interno del "Tercer Mundo", y reproducidas desde las esferas criollas del poder y los medios de comunicación que hacen eco de estos imaginarios. El resultado de este proceso es una subjetividad subdesarrollada (en lo que aquí importa sometida a la idea de desarrollo) dotada de rasgos particulares, o bien que culpa a un sector del "subdesarrollo" de una zona oprimida por su propia obstinación, en el caso que atañe, a los ecologistas, por ejemplo. Escobar agrega que

... solo desde una cierta perspectiva occidental tal descripción tiene sentido; su existencia constituye más un signo de dominio sobre el Tercer Mundo que una verdad acerca de él (...) el despliegue de este discurso en un sistema mundial donde Occidente tiene cierto dominio sobre el Tercer Mundo tiene profundos efectos de tipo político, económico y cultural que deben ser explorados (2014: 55).

Además, según este autor, es necesario realizar un profundo proceso de deconstrucción del desarrollo a través del análisis discursivo, con el objetivo de liberar el campo discurso y poder imaginar alternativas a esta forma de comprender y vivir el desarrollo. 
Sin embargo, será necesario tener claro que se trata de un discurso acompañado de prácticas, es decir, de toda una lógica que se materializa en la producción. Al respecto, Edelman dirá que

... el discurso, sin duda, figura en la reproducción de la pobreza espantosa que aflige a gran parte de la población mundial. Pero también los hacen otros fenómenos, como las formas de acumulación y distribución y los otros aspectos no discursivos sino sobre todo materiales de la reproducción física y social de las clases, los sectores, las corporaciones y los grupos familiares que constituyen toda economía moderna... (2005: 15).

Lo anterior viene al caso para no caer en la tentación de perder de vista que el desarrollo es un discurso que vehiculiza una serie de prácticas y trae consigo una relación social particular, concreta -la capitalista-, que

... provoca un conjunto de relaciones sociales que al mismo tiempo lo constituyen (...) esto no quiere decir que las personas estén únicamente constituidas a través del capital; más bien que la relación capital afecta o impacta en la totalidad de la realidad concreta de los individuos (León, 2015: 141).

De este modo, las relaciones sociales producidas por, y en, el capital son asimétricas. Dicho de otra forma, son consecuencia del modo de producción capitalista, el cual requiere, para su propia reproducción, discursos que lo sostengan y lo legitimen. De ahí que León sea enfático al afirmar que el capital provoca un conjunto de relaciones sociales constitutivas del capital, es decir, una relación dialéctica.

Resulta claro, entonces, que estos discursos del desarrollo, son ideológicos, y como ya se mencionó constituyen la "expresión contemporánea de la ideología del progreso". Se entenderá ideología "en un sentido relacional, brindando una base de organización para las creencias, subjetividades y valores de los individuos, con lo que se genera y reproduce un cierto orden social en sus múltiples dimensiones, desde lo individual a lo institucional" (Gudynas, 2010: 40). Por esta razón, dicha idea de progreso (hoy desarrollo) tiene un arraigo emocional y emotivo que forma parte de la construcción imaginaria de Latinoamérica.

Sin embargo, si se retoma esa deconstrucción a la que alude Escobar (2014), se debe decir que no es nueva y, como señala Gudynas (2010), existen alertas tempranas y fuertes críticas al desarrollo, incluso desde mediados de los años sesenta del siglo XX. Todas, por cierto, ligadas de una u otra forma a la idea de progreso, de avance, de una visión lineal; la cual está fundamentada en lo que Celso Furtado, desde 1975, calificó de mito. Según él, la idea de desarrollo fue utilizada para 
... movilizar a los pueblos de la periferia y llevarlos a aceptar enormes sacrificios, para legitimar la destrucción de formas de cultura arcaicas, para explicar y hacer comprender la necesidad de destruir el medio físico, para justificar formas de dependencia que refuerzan el carácter predatorio del sistema productivo (Gudynas, 2010: 21).

A partir de la cita anterior se pone en perspectiva cómo las críticas al desarro1lo, aunque duras, no pusieron en duda el crecimiento económico, y que no es hasta cuando se hace evidente, a través de un informe bajo pedido de los empresarios del Club de Roma al Massachusetts Institute of Technology (MIT), que ese crecimiento, considerado como ilimitado, efectivamente tenía un límite. Este puede calificarse de "ecológico", pues el tiempo de regeneración de la naturaleza no es el mismo que el de la reproducción del capital y de consumo de los bienes naturales. Dicho informe generó un gran debate en los años setenta, y puso en el centro de la discusión la cuestión del crecimiento y, por ende, del desarrollo.

Al mismo tiempo, la izquierda latinoamericana también hizo su propia crítica frente a "los límites del crecimiento", y en 1975 se presentó el documento ¿Catástrofe o Nueva Sociedad? Modelo Mundial Latinoamericano, coordinado desde la Fundación Bariloche, y liderado por Amílcar O. Herrera. Dentro de las principales conclusiones del informe se indica que

... los problemas "no son físicos sino sociopolíticos, y están basados en la desigual distribución del poder tanto internacional como dentro de los países". Como solución se propuso "una sociedad básicamente socialista, basada en la igualdad y la plena participación de todos los seres humanos en las decisiones sociales", donde se regularía el consumo material y el crecimiento económico para hacerlos compatibles con el ambiente (Gudynas, 2010: 26-27).

A pesar de los avances que presentó el informe, se siguió haciendo una defensa del crecimiento económico y una minimización del impacto ambiental a través del uso de la tecnología.

Gudynas (2012) menciona otros cuestionamientos al desarrollo y que daban más énfasis a alternativas y propuestas de reformulación con algunos en política social y económica, por ejemplo la propuesta de "otro desarrollo", que fue elaborada en 1975 por la Fundación Dag Hammarskjöld de Suecia. Esta plantaba que era necesario separar el desarrollo del crecimiento económico, y que el objetivo debería ser satisfacer las necesidades de la población y erradicar la pobreza, desde la endogeneidad (definida al interior de cada sociedad) y la autonomía. Esta perspectiva termina por individualizar las consecuencias del desarrollo, y hoy en día es uno de los principales aportes a la elaboración, en 1990, del "índice de desarrollo humano".

Así, es justamente al inicio de la década de los noventa cuando las críticas desde la ecología ecológica empiezan a tomar más forma y fuerza. A esto le sigue 
la resignificación del discurso dominante, la cual se produce siempre en tensión frente a las resistencias, o dicho de otra forma, hay tensiones y resignificaciones porque existe conflicto. Esto obliga a que se produzca una resignificación con el fin de invisibilizar las tensiones en que se disputan los sentidos. En fin, una constante dialéctica discursiva.

En el caso de Crucitas, esa tensión se singulariza en una matriz de país ecológico, y tiene sus propias particularidades, pero teniendo como referencia la discursividad globalizada en torno al ambiente, en contradicción abierta con el libre comercio. En Costa Rica, los gobiernos de las tres últimas décadas han aplicado de forma sostenida políticas neoliberales alineadas a la tesis de libre comercio, lo cual no quiere decir que no existan contradicciones internas, y que por ejemplo, el discurso del desarrollo haya dado un giro hacia la sostenibilidad a finales de la década de los noventa del siglo XX, al punto de que se ha construido una imagen de país ecológico. Una evidente resignificación del desarrollo y de lo ambiental, que ha formado el modelo el desarrollo.

Esta discursividad (y sobre todo sus consecuencias), aunque se le declare sostenible, está sostenida en una lógica de la maximización de los beneficios privados por encima del bien común. La contradicción entre sostenibilidad ambiental, derechos humanos y sociales, y, por otro lado, crecimiento y maximización de las ganancias, se hizo mucho más evidente en el gobierno de Óscar Arias Sánchez (2006-2010), cuando promulgó el "Programa Paz con la Naturaleza", mientras que declara, mediante decreto ejecutivo, de "interés público" y "conveniencia nacional" el proyecto minero en Crucitas, reabriendo un conflicto que parecía disipado con la moratoria declarada por Abel Pacheco en el 2003.

\section{Comprender Crucitas... tensiones por el desarrollo}

Cuando el 13 de octubre de 2008 se conoció que Óscar Arias Sánchez y Roberto Dobles, entonces ministro de Ambiente, habían firmado un decreto ejecutivo que declaraba de interés público el Proyecto Minero Crucitas se reabrió el conflicto, y con ello se hizo más grande la brecha entre el movimiento ecologista y una parte de los vecinos de Crucitas con el Gobierno, tan solo un año después de haberse aprobado el TLC con Estados Unidos, Centroamérica y República Dominicana.

Con un país dividido, el gobierno de Arias aprobó el decreto con la argumentación de que se generaría empleo y desarrollo en la zona "durante ese tiempo". Cabe acotar que solo mediante un decreto de este tipo era posible autorizar que Industrias Infinito iniciara las obras de extracción minera en Crucitas, pues había que destruir bosque primario. En todo caso, esa declaratoria de "interés público" respondía a una forma particular de entender el desarrollo. Concretamente el decreto dice, en su séptimo considerando: 
El proyecto Crucitas traerá varios beneficios económicos a la comunidad de San Carlos y el gobierno central. Entre estos beneficios están los siguientes: i) La mina tendrá una operación cercana a 11 años (incluye construcción, operación y cierre técnico). Esto significa que durante ese tiempo habrá desarrollo de las comunidades cercanas a Crucitas y necesidad de mano de obra... (Presidencia de la República, Decreto Ejecutivo N. 34801 MINAT, del 13 de octubre de 2008).

El decreto firmado por Arias y Dobles plasmó una forma de entender el desarrollo que hacía una equivalencia entre crecimiento económico, extracción, empleo y desarrollo (una matriz básica y clásica), que además estaba delimitada en el tiempo (11 años). Se podría interpretar que pasado ese tiempo se acabaría ese desarrollo, y Crucitas volvería a ser como antes, solo que con la naturaleza destruida. Aunque, de acuerdo con las condiciones del decreto, no habría tal destrucción porque la empresa se haría responsable del tratamiento de los químicos y de reforestar. Este es el discurso-promesa tanto del Gobierno como de la empresa.

Otra forma de comprender el desarrollo, en una línea similar, pero desde una visión liberal, puede ser la de Jorge Guardia (2002) en torno al extractivismo. En su habitual columna En Guardia publicada en el periódico La Nación, cuestionó en su momento algunas de las decisiones políticas del entonces presidente Abel Pacheco, y especialmente en lo relacionado con las garantías ambientales que por entonces estaban en discusión. Parte del texto de Guardia dice:

Otro tema controversial es elevar a rango constitucional las garantias ambientales (whatever that means). En eso no lo acompañaremos y le auguramos una fuerte oposicion. Tampoco es válido rechazar ad portas cualquier solicitud de explotación minera o petrolera cuando se permiten bajo estrictos requisitos de protección previstos en la legislación. Los recursos naturales deben estar al servicio del hombre, y no a la inversa. Porque generan riqueza y empleo. De nada sirven bajo tierra. El oro que contemplan los gusanos, que los disfruten los humanos (Guardia, 14 de mayo de 2002: s. p.).

Cuando Guardia dice whatever that means ("signifique lo que signifique"), lo que muestra es un desprecio total por los temas ambientales, y en especial por esa garantía constitucional impulsada por el gobierno de Pacheco. Al respecto, Guardia concibe a la naturaleza como un conjunto de recursos que deben explotarse, porque "están al servicio del hombre", y no es este quien está al servicio de la naturaleza, ni en armonía con esta. Dicha visión es propia de la modernidad y del utilitarismo más puro; es decir, se trata de una forma de entender el desarrollo en el que se excluyen las consideraciones ambientales en nombre de la riqueza (acumulación) y la generación de empleo (sin importar la calidad de estos).

En contraposición, surgieron voces disidentes con ese modelo de desarrollo, tanto en las mismas comunidades como en los sectores ecologistas y la academia. 
Por ejemplo, desde el inicio del proyecto, la Iglesia católica (desde sus comunidades de base) jugó un papel fundamental primero en la denuncia, y luego en la organización, difusión y argumentación de la ética cristiana, lo cual aporta una visión de mundo profundamente ecológica y espiritual. El oro y cuanto la Iglesia consideraba "migajas" fueron rechazados de plano, y contrapuesto con otra posibilidad de "un verdadero desarrollo". Así, salta otra idea del desarrollo, pero en esta ocasión desde la espiritualidad, en un pronunciamiento dirigido a las Comunidades Cristianas de Ciudad Quesada, los sacerdotes de la Diócesis de Alajuela manifestaron:

No necesitamos el oro para vivir, no necesitamos su brillo para tener salud, no requerimos de sus migajas para tener paz. Para nosotros Dios basta, y con Él podemos construir el verdadero desarrollo sin destruir lo que Dios creó para todos y todas (26 de noviembre 2008: s. p.).

Estos discursos también estaban presentes en el escrito de Henry Mora y Franz Hinkelammert (2005) cuando se habla de una economía para la vida y desde la teología de la liberación.

Las voces de académicos también entraron en el debate por el desarrollo; por ejemplo, Luis Paulino Vargas argumentó contra el proyecto minero, y sugirió que era necesario repensar las opciones de empleo y de lo que se ha entendido como desarrollo:

Con seguridad los habitantes de Las Crucitas, de Guanacaste o Siquirres podrían tener otras fuentes de empleo y vivir mucho mejor de como lo harian al depender de estas devastadoras actividades. Pero para ello se necesita de politicas de desarrollo de un signo distinto y, en fin, una economía que funcione bajo distintos criterios. Pero, para empezar, ello exige derrotar y expulsar el neoliberalismo (2008: s. p.).

Para Vargas (2008), el desarrollo debería tener "otro signo" y la economía otros criterios. Su opción es "derrotar y expulsar el neoliberalismo", es decir, entiende el problema del desarrollo desde la economía y como condición necesaria la derrota del dogma neoliberal, el enfrentamiento con el modelo de desarrollo en Vargas es abierto, y es la misma economía un instrumento para combatir el neoliberalismo. Esta discusión, como se mencionó, tuvo diversas formas y expresiones, de tal manera que los discursos tuvieron toda clase de matices desde las posiciones abiertamente utilitaristas hasta las más conservacionistas.

No todos los vecinos de Crucitas estuvieron en contra del proyecto minero, una parte de ellos estaban de acuerdo, pues desde su punto de vista habían estado durante décadas abandonados por el Gobierno. Por ejemplo, Carlos Alberto Vega, un vecino propietario de un taller mecánico opinó: 
Apoyo a la mina porque las comunidades han tenido desarrollo, mejoras en los caminos y puentes, ayuda en las escuelas, ellos siempre están dispuestos a colaborar, los que critican el proyecto no dan propuestas... los que se dicen ambientalistas allá que se oponen a la mina, todas las mañanas se levantan cogen la sierra y se van a cortar los árboles para vender madera, entonces, ¿cuál amor por la naturaleza? (Soto, 2013: 282).

'Vega no solo considera que el proyecto trae el "desarrollo", entendido como ayuda a las escuelas, mejores caminos y puentes, sino que también aumenta la posibilidad de tener fuentes de ingreso, es decir, aquello que el Gobierno no ha podido ofrecer, pero la empresa privada sí. Cuando menciona “... ellos siempre están dispuestos a ayudar...", podría contraponerse con quienes no han ayudado o quienes se oponen al desarrollo, en este caso el gobierno, y "los ambientalistas", a los que acusa de extraer madera de los bosques.

Finalmente, el Frente Norte de Oposición a la Minería emitió un comunicado el 8 de setiembre de 2008, en el que manifestaban

Que la minería es una de las actividades más contaminantes y destructoras del ambiente que existe. Destruye los bosques, contamina las aguas, degrada los suelos, mata la flora, la fauna y la vida humana. Amenaza la riqueza natural de los pueblos y pone en peligro mortal a nuestras comunidades (...) Que las y los habitantes de la Zona Norte creemos en un desarrollo sustentable, basado en la pequeña propiedad y no en una economía de enclave, depredadora del medio ambiente y de la sociedad en general (s. p.).

En este comunicado el Frente Norte de Oposición a la Minería deja clara su posición sobre el "desarrollo" que trae la empresa minera, y lo equipara con destrucción y amenaza a la vida, abogando por otro desarrollo de pequeña propiedad, contrario a la economía de enclave.

En las comunidades de Crucitas y aledañas no había consenso en torno al proyecto minero, en parte, el apoyo estaba generado desde la necesidad, desde la economía de subsistencia, desde el abandono de décadas parte de gobiernos que nunca se interesaron por generar proyectos o propuestas de desarrollo desde esquemas armónicos con el ambiente o respetando el criterio de las comunidades de la zona. Así que puede interpretarse que el apoyo que recibió la empresa tenía que ver con la inversión realizada alrededor para legitimar el proyecto, que hizo conexión directa con las necesidades de algunos de los vecinos. Mientras que otro grupo de vecinos comprendían el desarrollo y la vida desde otro lugar más armónico con la naturaleza.

\section{Conclusión}

Este somero recuento de hechos en torno a Crucitas ejemplifica cómo un proyecto empresarial de alto impacto ambiental trasciende lo administrativo y legal, y se 
convierte en una verdadera lucha política, en la que están de fondo las discursividades construidas sobre el desarrollo. Lo anterior aun cuando no todos los actores sociales y políticos no hicieran referencias explícitas a la cuestión del desarrollo. En el caso de Crucitas es posible ver con toda claridad que los operadores políticos traducen la lógica neoliberal en políticas públicas que tienen detrás intereses privados, y en este caso, estas intentaron favorecer abiertamente a Industrias Infinito.

En resumen, la resolución del conflicto se da dentro del marco del Estado de derecho, y es un tribunal el que terminó dictaminando que el proyecto minero contenía múltiples irregularidades. Esto no es un dato menor si se considera la desconfianza que los sectores sociales manifestaron en torno a los tribunales, es decir, la sentencia del Tribunal Contencioso Administrativo era un hito, antes de esa resolución, y la institucionalidad había funcionado para legitimar las acciones de la empresa minera.

Sin embargo, más allá de lo meramente legal, en el plano de lo político la disputa tenía como fondo modelos de desarrollo distintos, los cuales presentaron diferentes matices y se inscribieron en distintas tendencias, en muchas ocasiones sin que esto fuera consciente. Estos modelos de desarrollo fueron expresados a través de discursos que generaron sentidos que entraron en disputa o que reafirmaron otros comunes en una narrativa sobre lo ambiental. Entonces, a pesar de que el gobierno de Óscar Arias declaró la Paz con la Naturaleza, la declaratoria de interés público (en nombre del desarrollo) entraba en contradicción con el plan.

El problematizar el discurso oficial de la "Costa Rica Verde" pretende ubicar esta discursividad frente a las corrientes del ecologismo, y a la misma lógica interna de enunciaciación: ¿cuál es su utilidad política?, ¿cómo es que se instrumentaliza esta discursividad en el contexto de implementación de políticas neoliberales? Para ello habría que realizar un análisis de las políticas públicas de "desarrollo sostenible" y Costa Rica como país ecológico a las políticas de "Costa Rica verde" como marca país, enfocada a la "venta" del país destino turístico. Esto resulta de vital importancia, porque este discurso oficial entra en contradicción abierta con el proyecto minero y la tala de las 160 hectáreas de bosque primario, la discursividad oficial desprovista ya de la sutilidad ideológica, queda desnuda frente a la brutalidad de la destrucción transnacional, y la complacencia gubernamental. ¿Pudo esto ser un factor determinante? Es posible que fuese un factor, pero no está claro si el determinante, solo basta recordar que el discurso del desarrollo sostenible se inaugura en nuestro país hacia finales de la década de los noventa, y ya la lucha antiminera había iniciado a principios de esa misma década, así que sostener que el discurso de la Costa Rica Verde es el factor determinante nos puede desviar de una más adecuada interpretación. En todo caso, es posible que el imaginario de país sostenible sí haya influido en la movilización, así como el que impulsó de forma definitiva el proyecto minero haya sido Óscar Arias Sánchez.

Estos discursos tienen aparejadas cargas simbólicas sobre el territorio, es decir, que hay una construcción particular de la territorialidad. Las valoraciones que los 
discursos hacen del territorio se traducen en formas de hacer sobre el territorio, no solo de pensarlo. Estas valoraciones activan y modifican "a conveniencia" imaginarios, y cabe preguntarse ¿en este caso concreto cuáles eran esos imaginarios?, ¿cuál es la eficacia política del uso de la activación-construcción de estos imaginarios?

Se parte del hecho de que hubo una amplia producción discursiva y de muy diversos sectores y actores, que no siempre fueron conscientes todos que en el fondo había una disputa de sentidos, de significaciones, imaginarios, que sintetizaron la lucha por el territorio. ¿Cómo fue que un conflicto local se volvió nacional?, ¿qué sensibilidades se movieron? Quedan todas estas preguntas abiertas, apenas planteadas para responder con un trabajo más completo y con mucho mayor rigor metodológico.

\section{Bibliografía}

Antonelli, Mirta A. Minería transnacional y dispositivos de intervención en la cultura. La gestión del paradigma hegemónico de la "minería responsable y el desarrollo sustentable. Buenos Aires, Argentina: Editorial Biblos, 2009.

Barrantes, Alberto y Hernández, Carlos. "Fracaso de mina en Crucitas hunde a pueblo en el olvido". La Nación. 8 de enero de 2014, s. p.

Cartagena Cruz, Rafael. "El público vs. Placer Dome: comunicación y conflicto ambiental en el espacio público". Tesis para optar por el grado de licenciatura en comunicación con énfasis en relaciones públicas. Universidad de Costa Rica. Facultad de Ciencias Sociales. Escuela de Ciencias de la Comunicación Colectiva, 2000.

Edelman, Marc. Campesinos contra la globalización. Movimientos sociales rurales en Costa Rica. San José, Costa Rica: Editorial Universidad de Costa Rica, 2005.

Escobar, Arturo. La invención del desarrollo. Bogotá, Colombia: Editorial Universidad del Cauca, 2014.

Frente norte de oposición a la minería. Podemos vivir sin oro, pero no sin agua. Pronunciamiento del Frente Norte de oposición a la Minería. Federación Ecologista. Federación Costarricense para la Conservación del Ambiente, 2008. <http://www.feconcr.org/index. php?option=com_content\&task=view\&id=1073>.

Guardia, Jorge. "Columna En Guardia”, La Nación, 14 de mayo del 2002, s. p.

Gudynas, Eduardo. “Debates sobre el desarrollo y sus alternativas en América Latina: una breve guía heterodoxa". En Miriam Lang y Dunia Mokrani (Comps.). Más allá del Desarrollo. Quito: Fundación Rosa Luxemburgo/Abya Yala., 2012. 21-53.

León, Andrés. Desarrollo geográfico desigual en Costa Rica. El ajuste estructural visto desde la Región Huetar Norte (1985-2005). San José, Costa Rica: Editorial Universidad de Costa Rica, 2015.

Mora, Henry y Hinkelamert, Franz. Hacia una economía para la vida. San José, Costa Rica: DEI, 2005.

Morales, Evo. Discurso del Presidente Evo Morales en la inauguración de la Cumbre del G77: "Por una hermandad planetaria de los pueblos". Portal Web Rebelión, 2014. <http:// www.rebelion.org/noticia.php?id=186587>.

Nolasco, Silvia. Impactos de la minería metálica en Centroamérica. Centro de investigaciones sobre inversión y comercio (CEICOM). Conflictos mineros. Observatorio de conflictos mineros en América Latina (OCMAL), 2011. <http://www.conflictosmineros.net/ 
agregar-documento/publicaciones-ocmal/impactos-de-la-mineria-metalica-en-centroamerica/download>.

Presidencia de la República. Decreto Ejecutivo: 34801 MINAET del 13 de octubre de 2008. Declaratoria de interés público y conveniencia nacional el Proyecto Minero Crucitas.

Soto, Yokebec. La verdad a cielo abierto. Más de 20 años de historia de la mina Crucitas. San José, Costa Rica: s. e., 2013.

Svampa, Maristella. “La problemática de la minería metalífera a cielo abierto: modelo de desarrollo, territorio y discursos dominantes". En Maristella Svampa y Mirta Antonelli (Eds.), Minería Transnacional, narrativas del desarrollo y resistencias sociales. Buenos Aires, Argentina: Editorial Biblos, 2009. 29-46.

Svampa, Maristella. “Consenso de los commodities, giro ecoterritorial y pensamiento crítico en América Latina". Revista Observatorio Social de América Latina (OSAL) XIII, 32 (2012): 15-39.

Svampa, Maristella. "«Consenso de los Commodities» y lenguajes de valoración en América Latina". Revista Nueva Sociedad 244 (2013): 30-46.

Consejo Universitario de la Universidad de Costa Rica. Pronunciamiento sobre la declaratoria de interés público y conveniencia nacional de Proyecto Minero Crucitas. Acuerdo firme de la sesión N. 5303 del Concejo Universitario, miércoles 29 de octubre de 2008

Vargas, Luis Paulino. Maldesarrollo: a propósito del crimen de las Crucitas. Federación Ecologista, 2008. <http://feconcr.org/index.php?option=com_content\&task= view\&id $=1288>$.

Josué Arévalo Villalobos. Costarricense, obtuvo su Licenciatura en Psicología en la Universidad de Costa Rica, actualmente es egresado de la Maestría Académica en Ciencias Políticas con énfasis en Políticas Públicas y Gobernabilidad Democrática. Se desempeña como asesor de proyectos de Trabajo Comunal Universitario en la Vicerrectoría de Acción Social, y como profesor de la Escuela de Nutrición, ambos en la Universidad de Costa Rica.

Contacto: josue.arevalo@ucr.ac.cr 
